\title{
A Extensão da Ética como Filosofia Primeira para Emmanuel Lévinas
}

Lucila Lang Patriani de Carvalho

\section{Resumo:}

Contrariando o pensamento filosófico de seu tempo, Emmanuel Lévinas coloca, dentro de seu sistema, a Ética como Filosofia Primeira e não mais a Ontologia, como ocorria até então. Esta substituição é justificada pelo filósofo que, com esta mudança, altera também a forma de pensar a Alteridade e as relações entre esses Sujeitos. Os novos moldes adquiridos formam uma Filosofia do Amor, reformulam a Humanidade do Eu e do Outro e passam por diversos conceitos que estruturam positivamente esta relação, estabelecendo sempre contato com o Infinito.

Palavras-Chave: Emmanuel Lévinas, Ética, Fenomenologia, Alteridade. 
A Teologia e a Filosofia, mais especificamente a Metafísica, caminham em constante comunicação, com uma linha tênue que distingue o viés de temas compartilhados por ambas e que se tornam comuns pelo fato de estas análises não se restringirem somente ao campo do sensível. Variando de acordo com o filósofo e a sua abordagem, esta aproximação pode ser maior ou menor, ou mesmo chegar ao ponto de uma confusão indissociável. Emmanuel Lévinas é um dos autores que tiveram sua obra dividida e sua posição questionada por seus leitores, caracterizando-o ora como filósofo, ora como teólogo e, em decorrência disto, como um filósofo do judaísmo.

Até recentemente Lévinas era pouco conhecido e estudado, mas isto vem se modificando ultimamente. Conforme sugere Poirié: "talvez porque a época seja mais moral do que política. Talvez também porque hoje um filósofo que fala de Deus e de espiritualidade não seja mais banido do rol dos pensadores 'sérios", ', onde tais divisões por áreas perderiam a sua razão de ser.

Sua obra não se resume a nenhuma das duas áreas exclusivamente, nem mesmo forma um todo coeso que procura a fusão entre Teologia e Filosofia. Lévinas fez tanta questão de abordar esses campos separadamente que chegou a designar editoras diferentes para publicar as suas obras: uma para as que considerava como sendo de Filosofia pura (por exemplo, Ética e infinito, Entre-nós...) e outra para os seus livros sobre estudos judaicos (com as leituras Talmúdicas). Os estilos de escrita e os objetivos em cada um destes grupos de obras são diferentes. A melhor caracterização, dentro deste contexto, seria tratar o autor como filósofo e como estudioso judeu, distintamente.

Para manter esta separação incisiva, Lévinas nunca negou sua origem judia e a importância do judaísmo em sua vida pessoal e em seus estudos. Não se importava em ser considerado como um "filósofo judeu", ${ }^{2}$ mas tal termo implicava algumas delimitações específicas. Também não queria ser visto como um pensador judeu que lida com o judaísmo de forma exclusivamente dogmática e sistemática, apoiando todas as explicações unicamente nos Textos Sagrados. Porém, embora sem esquecer toda esta tradição da religião, ele queria que seus estudos passassem pela crítica filosófica, buscando a racionalidade presente atrás destas explicações de aparência puramente dogmática.

Se procurava ser tão metódico ao separar a Filosofia da Teologia em suas produções, a sua formação não se deu sistematicamente da mesma forma. Podemos ressaltar ao menos três áreas de grande importância ao longo de sua vida ${ }^{3}$ que fazem com que tanto suas influências como seus interesses sejam postos em debate em suas obras, as quais passam por diversas temáticas humanas.

I POIRIÉ, François. Emmanuel Lévinas: ensaio e entrevista. p. II.

2 Para uma visão mais aprofundada a respeito desta discussão em uma entrevista com o filósofo, Cf. Ibidem, Ibid. p.IO2.

3 Gf. POIRIÉ, François. Emmanuel Lévinas: ensaio e entrevista. p. IO. 
A primeira a se ressaltar é a História e o decorrente viés político desta. Ainda quando pequeno, nascido em Kovno, na Lituânia, Lévinas teve que fugir, com a sua família, da Grande Guerra de I9I4. Essa mudança possibilitou a posterior vivência local da Revolução Russa e, quando tempos depois se muda para a França para desenvolver seus estudos filosóficos, presencia o nazismo de Hitler, guerra durante a qual fora prisioneiro e perdera grande parte de sua família.

Em meio a esses fatos tão conflituosos, contrários às interpretações positivas que a Alteridade possa adquirir, torna-se curioso observar como isto é subvertido, gerando efeitos inversos na filosofia de Lévinas, que, por sua vez, não cria um sistema belicoso e refratário ao Outro, mas um modelo de compreensão e tolerância, pautado pela receptividade presente no feminino.

Um segundo ponto, também relacionado às fugas políticas, é a origem judia de sua família que, adicionada à influência da leitura da Bíblia, molda a importância que a religião adquire no decorrer de sua obra, por meio de um viés espiritual que introduz no campo concreto das relações intersubjetivas o conceito fundamental e divino de "amor ao próximo".

O terceiro a ser citado, responsável por sua formação intelectual preliminar e por introduzi-lo à Filosofia, é o seu contato próximo com a Literatura, principalmente com os grandes escritores russos (como Gógol, Dostoiévski, Tolstói, Lermontov etc.), que formularam conceitos e situações que servirão como base e exemplo para Emmanuel, com referências interdisciplinares que perpassam a sua produção.

O ponto de convergência temático da filosofia de Lévinas, responsável pelos conflitos entre aqueles que pretendem caracterizar sua obra como teológica e os que não a pensam deste modo, é a importância da Ética e o desenvolvimento dos temas a ela aliados (como a Epifania, o Desejo, o Outrem, o Bem, a Responsabilidade, entre outros) e que determinam a sua configuração. A primeira coisa a perceber em sua exposição é o primado da Ética que, com o conceito de Alteridade, acaba por orientar a maior parte do desenvolvimento de sua filosofia.

\section{O Primado da Ética}

A maior influência para Emmanuel Lévinas, assim como para grande parte dos filósofos da França contemporânea, que teve em Sartre um de seus mais reconhecidos representantes, originou-se no pensamento alemão. Por meio das vozes de Husserl e de Heidegger, a Fenomenologia se tornou conhecida e fincou raízes em outros países. No caso da França, esta difusão deve-se em grande parte a Lévinas, que atuou como tradutor e estudante precoce de ambos os filósofos. 
A Fenomenologia busca um estudo dos próprios fenômenos, abordando o aparecimento destes a uma consciência intencional, isto é, esta como sendo sempre consciência de alguma coisa. Tal abordagem origina uma grande importância do Ser, confirmando o estudo e o primado da Ontologia, o que ocorre em Heidegger e Sartre, por exemplo.

Lévinas, na contramão de seu tempo e de toda uma tradição filosófica anterior, não acredita mais em ser a Ontologia a Filosofia Primeira, mas, para ele, a Ética é a que ocupa esta posição. Esta substituição não é uma busca por suprimir a Ontologia, mas se dá como uma ampliação do foco: em vez de abordar as relações com uma visão individualista - propósito da Ontologia -, a ética passa às relações em si, dando privilégio à posição do Outro.

É uma mudança de paradigma, da autonomia de um Ser Mesmo (conforme será mais bem exposto adiante) e da caracterização de sua existência para a Ética, que respeita a heteronomia e não tem o seu ponto central no Mesmo, mas no Outro, e, deste modo, articula a existência como um todo. O desenvolvimento filosófico não encontra mais o seu centro no sujeito isoladamente, mas no exterior do Outrem.

Esta proposta de relacionar a Ética à Ontologia, em seu livro Totalidade e infinito, é dada de forma a ser aquela uma "defesa da subjetividade, mas [que] não a captará ao nível do seu protesto puramente egoísta contra a totalidade". ${ }^{4}$ É pensar a relação do Eu com o exterior, com o Outrem (absolutamente Outro), de forma que seja necessário abordar ambos os temas, pois "a alteridade só é possível a partir de mim", 5 embora o seu desenvolvimento doutrinário só tenha sucesso uma vez que não fique presa unicamente à ideia do Eu, que consiga ultrapassá-la.

A Ontologia, por outro lado, que reduz o Outro ao Eu, ao Mesmo, é uma egologia, que receberá a crítica de Lévinas como sendo uma Filosofia do poder e da dominação, que nunca coloca este Eu central em questão. Neste cenário da filosofia contemporânea a Lévinas há o diagnóstico de uma crise do Humanismo, ${ }^{6}$ o qual é necessário, então, reformular, conferindo maior importância à condição do Outro.

A proposta levinasiana, para outra Filosofia Primeira, ficará mais clara com o desenvolvimento das configurações desta Ética pela formulação da Alteridade, na oposição entre o interior e o exterior. Seu ponto referencial para tanto, como observa Poirié, é "entre nosso aprisionamento em nós mesmos, nossa intimidade incompartilhável, e o mundo dos outros - sociedade, Estado".?

4 LÉVINAS, Emmanuel. Totalidade e Infinito p. I3.

5 Ibid. p. 27.

6 Cf. LÉVINAS, Emmanuel. Humanismo do outro homem. p.7I.

7 POIRIÉ, François. Emmanuel Lévinas: ensaio e entrevista. p. 25. 


\section{A Alteridade}

Ao abordar a Alteridade, a presença de outra consciência para um ser consciente, podemos concebê-la de duas formas. A primeira coloca os dois sujeitos participantes em posições de completa desigualdade, sendo que enquanto um adquire a condição de Sujeito, o Outro é diagnosticado como um mero objeto para aquele. Este viés de concepção sobre as relações intersubjetivas é o adotado por Jean-Paul Sartre, conhecido pela famosa frase, da peça Entre quatro paredes, "O inferno são os outros", justamente pela relação ser sempre caracterizada como de um Sujeito em relação a um objeto, com implicações limitantes nesta configuração. A partir desta formulação, mesmo quando o Eu vê o Outro como um Sujeito, este Outro está lidando com o Eu como sendo um objeto, nunca concretizando a posição de dois Sujeitos simultaneamente.

A segunda maneira, segundo a qual é possível manter as duas partes como sujeitos (não necessariamente em igualdade, como será abordado mais adiante, mas sem colocar nenhuma das duas como um objeto), é a que Lévinas tenta manter no desenvolvimento de seu pensamento. $\mathrm{O}$ egotismo, característico de um ser que se esgota em si mesmo, não tem espaço dentro deste sistema; há a necessidade do Outro continuar em sua posição de Sujeito, de pensar uma Filosofia do Amor.

Para que haja o sucesso de tal tolerância, é preciso pensar o Outrem como um absolutamente Outro, característica reforçada diversas vezes em suas obras, para que este não se confunda com o Eu, que recebe a denominação de Mesmo, em decorrência de sua identidade consigo mesmo. ${ }^{8}$ Este Eu é um Ser-paraOutrem, no melhor sentido moral, e com a carga de doação que este "para" possa adquirir. Tal separação não permite que o Outro seja englobado e se torne também o Mesmo, que é o que ocorre em uma relação entre Sujeito e objeto, ponto essencial para compreender o que Lévinas busca ao distinguir o propósito da Ética e o da Ontologia.

A Ética é a via que possibilita a relação do Mesmo com o Outrem nestes moldes e "a relação com outrem, portanto, não é Ontologia. Este vínculo com outrem que não se reduz à representação de outrem, mas à sua invocação, e onde a invocação não é precedida de compreensão, chamo-a religião. A essência do discurso é oração", 9 com a devida concepção do termo religião, não como uma expressão da Teologia ou uma forma institucional, mas como uma formação originária nas relações entre os Sujeitos.

Esta separação coloca as duas partes em distanciamento, conservando o Outro como Sujeito estranho, como um estrangeiro. Neste vão que se forma de

8 POIRIÉ, François. Emmanuel Lévinas: ensaio e entrevista. p. 25.

9 LÉVINAS, Emmanuel. Entre nós: Ensaios sobre a alteridade. p .29. 
um Sujeito para o Outro, surge o Infinito, um campo onde o Eu pode pensar mais do que pensaria sozinho, pois está em contato com o exterior, que permite diversos modos de interação, mas, já cabe salientar previamente, sempre orientadas para o Bem.

$\mathrm{Na}$ forma ontológica temos uma relação conflituosa de dominação e assimilação, um sujeito objetiva o outro por meio do exercício de sua liberdade. Por outro lado, na Ética, os limites de cada Sujeito são respeitados, a distância entre ambos nunca é suprimida e, desta forma, não se atinge uma totalização. A concepção do Infinito é importante neste ponto, mantendo as duas partes separadas e irredutíveis entre si, possibilitando que as relações ocorram harmonicamente neste cenário.

O Infinito, Absoluto, não coloca o Outro como um Homem-Deus, ${ }^{10}$ mas como uma forma de expressão deste Infinito, um encontro em que há a palavra de Deus, um encontro com o Divino, em que o individual entra em contato com o que lhe é exterior.

\section{No campo do Entre-nós}

Dada a concepção de Alteridade, a Ética não é uma formulação feita em um debate posterior a este encontro, como é uma positivação jurídica, por exemplo. Ela é imediata ao contato, formando o campo do "Entre-nós", o campo dos Sujeitos éticos, onde reside propriamente a humanidade de cada um e que abre a dimensão do Divino.

Aberto o Infinito na distância entre o Eu e o Outro, há a possibilidade de se passar a pensar o que é exterior ao pensamento do Eu, situação que surge frente ao absolutamente Outro, ao desconhecido. Decorrente desta abordagem, há a ideia do acolhimento hospitaleiro deste estrangeiro que é o outro, mediante a superação do pensamento individual, com "o fato surpreendente de conter mais do que é possível conter". II

Este primeiro contato é feito por intermédio da face do Outro, pela Epifania de um rosto que traz consigo o apelo e o imperativo de Respeito e Responsabilidade. Neste ponto já se forma a desigualdade em relação ao Outro, não pelo fato da objetivação de qualquer uma das partes, mas pela superioridade do Outro nesta relação, pelas minhas obrigações com o Outro, sem qualquer poder ou dominação sobre o Outro, já que este me ultrapassa e é mantido como Sujeito.

Io Gf. LÉVINAS, Emmanuel. Entre nós: Ensaios sobre a alteridade. p.I5I .

II LÉVINAS, Emmanuel. Totalidade e Infinito p.I4. 
A aspiração exterior é o Desejo que, aliado à Linguagem, confere uma função pedagógica ao Outro, que ensina ao Eu, transmitindo o que este ainda não sabe. ${ }^{12}$ "Aqui a fórmula 'antes de estar em relação com um ser é preciso que eu o tenha compreendido como ser' perde sua aplicação estrita: ao compreender o ser, digo-lhe simultaneamente minha compreensão", ${ }^{13}$ privilegiando a instantaneidade da relação e da comunicação, que reforça isto. A função de revelação de um Ser e seu Infinito para o Outro é dada pelo ensino e pela Linguagem, "só o absolutamente estranho nos pode instruir". ${ }^{\text {I4 }}$

$\mathrm{Na}$ relação de um Sujeito com o Outro nunca haverá uma certeza absoluta e um conhecimento pleno e totalizante do campo do Entre-nós. Este modo de se relacionar sempre esbarra no limite do desconhecido, mas com uma ressalva: "o fim da certeza pode ser o início da confiança". ${ }^{\text {I5 }}$

A partir deste desconhecido se forma uma relação pautada no Respeito e na Responsabilidade, uma Ética cega na qual a "moral do respeito supõe a moral do amor. O amor torna cego o respeito que, impossível sem cegueira em relação ao terceiro, não é senão uma piedosa intenção esquecida do mal real". ${ }^{16}$ Em uma relação Ética, só o que é garantido é o que se dá, o que cada um coloca neste Entre-nós; não há a previsão de um retorno, algo que igualmente obrigue o Outro ao Respeito e à Responsabilidade destinadas ao Eu. O Sujeito estabelece relações totalmente desinteressadas e livres de influências exteriores.

\section{Ampliação do campo Ético}

A Ética, justamente por se posicionar anterior a qualquer outro desenvolvimento teórico que possa surgir a partir do Entre-nós, acaba também por ser suprateológica e suprajurídica. A explicação para isto é a segundo a qual as religiões ou as leis não conseguem abarcar todo o seu conteúdo e sistematizá-lo.

A Responsabilidade (e o mesmo ocorre com o Respeito) é um dos exemplos de conceitos que encontram um diferencial de carga entre a parte Jurídica e a Ética. A primeira consistiria meramente em uma responsabilidade individual do próprio Sujeito perante a Lei. No campo ético a responsabilidade é pelo Outro, não por obrigação, mas por delicadeza e por uma solicitude que não pensa a via de mão dupla em que o Outro igualmente suporte o Eu.

I2 Ibid. p. I62.

I3 LÉVINAS, Emmanuel. Entre nós: Ensaios sobre a alteridade. p. 28.

I4 LÉVINAS, Emmanuel. Totalidade e Infinito p. 60.

I5 HADDOCK-LOBO, Rafael. Da existência ao Infinito: ensaios sobre Emmanuel Lévinas. p. I8.

I6 LÉVINAS, Emmanuel. Entre nós: Ensaios sobre a alteridade p. 43. 
A "Responsabilidade não é aqui fria exigência jurídica", ${ }^{17}$ ela é parte integrante do Amor ao próximo, ela é "pressuposta por toda a cultura literária, por todas as bibliotecas e toda a Bíblia, em que se relata sua sublimação e sua profanação", ${ }^{18}$ que dependem do modo pelo qual o Eu lida com a sua Responsabilidade. Mas esta orientação, para Lévinas, é estabelecida em prol de uma relação pacífica, pautada pelo Bem, que, assim como o Respeito, não é uma posição de sujeição, mas de ensino e comunicação mútuos no Entre-nós.

A estes conceitos tratados, acrescenta-se o de Justiça (que posteriormente, receberá a especial atenção de Jacques Derrida), que guardará estreita relação com a linguagem e a referência desta com os objetos, com o intuito de justificálos. ${ }^{19}$ Nas relações intersubjetivas, a Justiça também não tem relação com a submissão e, como os demais conceitos aqui tratados, não é posta em prática através das Leis Universais, mas guiada pela Bondade. É estabelecida uma forma peculiar de se fazer Justiça, pautada pelo Respeito e Responsabilidade, "que comporta julgamento e comparação, comparação daquilo que, em princípio, é incomparável, pois cada ser é único; todo outrem é único”. ${ }^{20}$

Para arrematar esta Filosofia do Amor, de absoluta tolerância, seria cabível estender para todo o campo de relações intersubjetivas o que Lévinas pensa sobre a Justiça nestes moldes: "Quero descrever a relação homem a homem. A justiça não a constitui, é ela que torna a justiça possível", ${ }^{21}$ partindo do pressuposto de que todo o Bem, o Infinito, Deus, que existe no Entre-nós, estabelecerá as Relações Éticas.

\section{Referências bibliográficas.}

LÉVINAS, Emmanuel. Entre nós: Ensaios sobre a alteridade. Petrópolis, RL: Vozes, 2004 .

Éthique ef Infini: dialogues avec Philippe Nemo. Paris: Fayard, 2008.

Humanismo do outro homem, Petrópolis, RJ: Vozes, I993.

I7 Ibid. p. 238.

I8 Ibid. p. 238.

I9 HADDOCK-LOBO, Rafael. Da existência ao Infinito: ensaios sobre Emmanuel Lévinas. p. I54.

20 LÉVINAS, Emmanuel. Entre nós: Ensaios sobre a alteridade p. I44.

2I Ibid. p. 62. 
Totalidade e Infinito Lisboa, Portugal: Edições 70, 1988.

HADDOCK-LOBO, Rafael. Da existência ao Infinito: ensaios sobre Emmanuel Lévinas. São Paulo: Loyola, 2006.

POIRIÉ, François. Emmanuel Lévinas: ensaio e entrevista. São Paulo: Perspectiva, 2007.

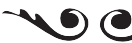

Lucila Lang Patriani de Carvalho é graduanda em Filosofia pela USP.

E-mail: lu_lang_9@hotmail.com 